\title{
MENGUNGKAP MASALAH PEMBACAAN PRASASTI PASRUJAMBE
}

Oleh: M.M. Sukarto K Atmodjo

Pêpaliku ajinên mbrekati. ${ }^{1}$

Tur sêlamêt sarta kuwarasan.

Pêpali iku mangkene.

Aja agawe angkuh,

Aja ladak lan aja jail.

Aja ati sêrakah,

Lan aja cêlimut,

Lan aja mburu alêman,

Aja ladak wong ladak pan gêlis mati,

Lan aja ati ngiwa.

Sapa sapa wong kang gawe bêcik,

Nora wurung mbenjang manggih arja,

Têkeng saturun-turune.

Yen sira dadi agung,

Amarintah marang wong cilik,

Aja sadaya-daya,

Mundak ora tulus,

Nggonmu dadi pangauban.

Aja nacah marentaha kang patitis,

Nganggoa têpa-têpa.

R.M. Soetardi Soryohoedoyo: Pepali Ki Ageng Selo, diterbitkan oleh: CV "Citra Jaya". Surabaya, 1980.

Dalam buku Laporan Tahunan Dinas Purbakala (Departemen PP dan K) tahun 1954 (terbit tahun 1962) mengenai prasasti Pasrujambe tertulis pada halaman 12 sebagai berikut (ejaan lama): "Di desa Pasrujambe (Senduro, Lumadjang) didapatkan gundukan tanah dengan batu ${ }^{2}$ kali besar dan ketjil. Di antara batu-batu tadi ada 16 buah jang bertulisan. Penelitian tehadap tulisan ini tidāk memberikan sesuatu hasil, bahkan djenisnjapun dari tulisan itu tidak dapat diketahui (gb. 15)". Selanjutnya keterangan di bawah gambar 15 berbunyi: "Senduro (Lumadjang). Batu bersurat jang tulisannja gandjil. Foto DP 19427". 
Sejak membaca keterangan dalam Laporan Tahunan tersebut. sebetulnya saya ingin secepatnya melakukan pengamatan ke desa Pasrujambe, tetapi keinginan itu baru terlaksana setelah 20 tahun kemudian. Tepatnya pada tanggal 22 Desember 1983 menjelang hari raya Natal, dengan membonceng sepeda motor Sdr. Abdul Choliq Nawawi dari Lumajang, dan dalam suasana hujan lebat setelah tiba di Pasrujambe. saya berhasil mencapai tempat lokasi batu bersurat tersebut. Prasasti singkat yang semuanya berjumlah sekitar 20 buah itu terdapat di dukuh Munggir. Desa Pasrujambe. Kecamatan Senduro, Kabupaten Lumajang. Prasasti bertebaran di dekat sebuah sumber yang sangat jernih airnya bernama sumber Rawa. Sebatang sungai kecil yang mengalir di dekatnya disebut pula Kali Rawa. Rupa-rupanya sumber Rawa itu pada jaman dahulu (Majapahit). selain digunakan untuk keperluan sehari-hari, juga dianggap sebagai sumber air hayat (air amrta). ${ }^{2}$ Seperti telah diketahui air adalah sumber hidup (fons vitae). ${ }^{3}$ Lebih-lebih letak dukuh Munggir (desa Pasrujambe) memang di kaki bagian timur Gunung Semeru yang dianggap keramat pada jaman dahulu. Menurut cerita (mitologi) di dalam kitab Tantu Panggêlaran. Gunung Semeru merupakan sebagian dari puncak Gunung Mahameru di India yang telah dibawapindah ke pulau Jawa. ${ }^{4}$

Prasasti Pasrujambe terdapat di sebuah dataran sekitar sumber Rawa maupun di atas gundukan tanah atau perbukitan di sekelilingnya. Sayang sekali pada waktu itu hujan bertambah lebat sehingga kami berdua basah kuyup dan harus berlari-lari pindah tempat mencatat tulisan. Terdorong oleh perasaan ingin mengetahui dan menebak teka-teki isi prasasti yang dinyatakan jenis tulisannya ganjil dan tidak dapat diketahui tersebut (Laporan Tahunan 1954), saya berusaha mencatat dan membaca sebaik-baiknya. Sementara itu Sdr. Abdul Choliq Nawawi memayunginya dengan daun pisang dan membantu pula mencatat ukuran prasasti batu tersebut. Perlu saya je!askan bahwa beberapa waktu sebelumnya (19-9-1981) serombongan peneliti prasasti dari Jakarta pernah pula melakukan penelitian ke Pasrujambe dan diantar oleh Sdr. Abdul Choliq Nawawi. Ternyata hasil pembacaan saya dengan penelitian sebelumnya kadangkadang sangat berlainan. Sebuah batu berukuran: panjang $25 \mathrm{~cm}$ dan lebar $15 \mathrm{~cm}$ yang dipahat dengan 3 baris tulisan dan dibaca oleh seorang anggauta tim sebelumnya berbunyi: rabut macan pajak. 
menurut pengamatan saya harus dibaca: rabut macan pêtak (Gb. I). Perkataan rabut (rambut) 5 berarti: Yang Suci, Yang Mulia atau Yang Terhormat, biasanya dikaitkan dengan nama tempat atau nama bangunan suci, misalnya: Rabut Jalu (Par. hlm. 3, nama tempat), Rabut Katu dan Rabut Gorontol (Par. hlm. 5, nama tempat), Rabut Kẹdung Panitikan dan Rabut Gunung Lêjar (Par. hlm. 8, nama tempat, gunung), Rambut Siwi (nama pura di Kabupaten Jembrana, Bali) dan Rambut Monte (nama candi di sebelah timur-laut Blitar). Karena prasasti singkat itu menyebut nama Macan pêtak, rupa-rupanya tulisan tersebut dipahat oleh seorang pejiarah (pelaku siddhayātra) dari daerah Macanputih (Banyuwangi) yang ingin mendaki Gunung Semeru untuk maksud-maksud tertentu ( $p e \hat{t a k}=$ putih). Demikian pula pembacaan pat bawi ternyata harus dibaca prtiwi, pateçatu sebetulnya pangestu, ghang mami seharusnya yang mami, dan lain-lain.

Seperti telah diterangkan di atas, jumlah prasasti di dukuh Munggir (desa Pasrujambe) cukup banyak, karena itu untuk sementara waktu saya hanya akan membahas sebuah di antaranya yang ter golong agak panjang isinya. Hanyalah terlebih dahulu perlu saya jelaskan bahwa tiga buah batu bertulis dan bergambar sekitar tahun 1979 telah dibawa-pindah oleh seorang mahasiswa ke kota Jember. Sekarang tiga buah batu penting itu disimpan dengan baik di Fakultas Sastra Universitas Negeri Jêmbêr. Hasil penelitian saya pada tanggal 20 Agustus 1986 di Fakultas Sastra Jember membuktikan bahwa bentuk (tipe) tulisan tersebut tepat sama (persis) dengan batu bertulis yang masih terdapat di Pasrujambe. ${ }^{6}$ Perincian ketiga buah batu itu lengkapnya sebagai berikut (Gb. II):

I. Sebuah batu berukuran: panjang $39 \mathrm{~cm}$, lebar $20 \mathrm{~cm}$ dan tebal $8 \mathrm{~cm}$ digores dengan dua barus huruf Jawa Kuno berbunyi:

1. i saka

2. 1381

II. Sebuah batu berukuran: panjang $33 \mathrm{~cm}$, lebar $27 \mathrm{~cm}$ dan tebal $8 \mathrm{~cm}$ digores dengan tiga baris huruf Jawa Kuno berbunyi:

1. sang

2. nawakr

3. nda 
IIl Sebuah batu berukuran: panjang $35 \mathrm{~cm}$, lebar $26 \mathrm{~cm}$ dan tebal $8 \mathrm{~cm}$ digores dengan sebuah diagram ${ }^{7}$ menggambarkan yantra (Inggris: tool, aid), yaitu semacam alat pembantu dalam melakukan meditasi (yoga).

Tahun 1381 Saka (1459 M) berada dalam jaman pemerintah Bhre Wêngkêr yang naik takhta menjadi raja di Majapahit dengan gelar Hyang Purwawiśesa. Menurut kitab Pararaton, setelah Sang Sinagara Sri Rajasawarddhana meninggal, selama tiga tahun antara 1453 - 1456 M kerajaan Majapahit dalam keadaan 'inter regnum' (telung tahun tan hana prabhu). ${ }^{8}$ Inter regnum ini berakhir setelah Bhre Wengker naik takhta pada tahun 1378 Saka (1456 M)dan meninggal serta di-dharmma-kan di Puri pada tahun 1388 Saka (1466 M). Kemudian pada tahun itu juga Bhre Pandan Salas (Dyah Suraprabhāwa) menggantikannya menjadi raja di Majapahit. Maka jelaslah sudah bahwa prasasti Pasrujambe yang tersimpan di Fakultas Sastra Jember (1381 Saka) dipahat dalam jaman pemerintahan Bhre Wêngkêr (1378 - 1388 Saka). Pada waktu itu kekuasaan negara Majapahit sudah mulai berkurang, dan akhirnya kira-kira 70 tahun kemudian Majapahit betul-betul mengalami kehancuran total ( $\pm 1525 \mathrm{M}$ ).

Selanjutnya mengenai nama Sang Nawakrnda (berarti: sembilan keranda atau wadah) ${ }^{9}$ dapat diperkirakan bahwa nama itu rupa-rupanya berkaitan dengan nama seorang pendeta atau mungkin pula nama dewa penjaga setempat (local deity). Tentu saja kemungkinan lainnya tidak tertutup sama sekali. ${ }^{10}$ Andaikata Sang Nawakrnda memang seorang pendeta maka dapat diperkirakan bahwa tokoh itu melakukan tapa-brata (yoga) di dukuh Munggir (desa Pasrujambe) ${ }^{11}$ pada tahun sekitar 1381 Saka dengan menggunakan alat bantuan yantra untuk melakukan meditasi (samadi). Apabila dugaan ini benar maka pendeta itu rupa-rupanya seorang penganut aliran Tantrāyana. Perlu ditambahkan di sini bahwa sewaktu saya melakukan penelitian di Pasrujambe juga menemukan dua buah batu lainnya yang dipahat dengan angka-tahun 1381 Saka. Bentuk tulisannya hampir sama dengan batu berangka-tahun yang disimpan di Jember. Selain itu juga terdapat sebuah batu Bertulis yang dipahat dengan nàma seorang pendeta, yaitu Bagawan Citragotra (tiga baris). Beberapa buah bati lainnya dipahat dengan tulisan berbunyi: Sang Balasariwu (tiga baris). 
dudukuna (dua baris), walering-ababad wong samadı (tiga barıs. dan lain-lainnya. Perkataan singkat itu masing-masing berarti: Sang Balaseribu (bala $=$ tentara, sariwu = seribu). supaya pergi ke dukun, dan pantangan (batas) untuk orang yang membuka hutan dan bersamadi (waler = larangan, batas, ababad = membuka hutan, wong $=$ orang, samadi $=$ tapa). Berdasarkan beberapa temuan tersebut, maka sekarany dapat disimpulkan bahwa di Munggir (desa Pasrujambe) setidak-tidaknya terdapat tiga buah batu ber angka-tahun 1381 Saka (dua buah masih di Munggir dan sebuah lainnya di Jember) dan situs itu dahulu digunakan untuk tempat jiarah (siddhayātra dan tirthāyātra) ${ }^{12}$ atau tempat bersamadi (bertapa) beberapa orang pendeta.

Seperti telah saya singgung di atas, untuk sementara waktu saya hanya akan membahas secara singkat sebuah prasasti dari Pasrujambe yang tergolong agak panjang isinya, sedangkan tulisan singkat lainnya seperti beberapa contoh di atas akan saya uraikan pada kesempatan lain. Batu bertulis yang agak panjang itu terdiri atas enam baris akșara (huruf) Jawa Kuno dan dipahat di bagian permukaan batu yang halus dan rata. Batu berukuran: panjang $66 \mathrm{~cm}$, lebar (garis-tengah) $49 \mathrm{~cm}$ dan tebal $8 \mathrm{~cm}$ (Gb. III). Transkripsi selengkapnya lebih-kurang sebagai berikut:

1. Iki pangestu

2. yang mami, guru gu-

3. ru yen-arabi, de-

4. $n$ kadi boting ngaka-

5. sa lawan prtiwi

6. papa kabuktihi.

Berarti:

1. Inilah restu

2. dari para dewa, para

3. guru kalau kawin (beristri), agar

4. seperti beratnya angkasa

5. dan pertiwi (bumi),

6. semoga terbukti penuh (siapa yang melanggar, supaya mendapat kesengsaraan). 
Bunyi dan maksud prasasti singkat di atas sudah cukup jelas. yaitu nasihat kepada para guru (pendeta) apabila beristri supaya saling mencintai bagaikan beratnya (akrabnya) persatuan antara angkasa (laki-laki) dan bumi (perempuan). Maksudnya agar perkawinan tersebut kekal abadi dan tidak terpisahkan. seperti persatuan antara Bapa Akasa dan lbu Pertiwi. Hal ini dapat dibanding pula dngan ungkapan kata dalam bahasa Jawa Baru 'kaya mimi lan mintuna' (bagaikan mimi dan mintuna) ${ }^{13}$ dan 'sakurêbing langit salumahing bumi' (tertelungkupnya langit tertelentangnya bumi). ${ }^{14}$

Menarik perhatian bahwa istilah pangestu ternyata sudah dikenal setidak-tidaknya sejak jaman Majapahit akhir (sekitar tahun 1459 M). Perkataan pangestu inilah yang dibaca oleh rombongan tim sebelumnya pateçatu. Kemudian bota ika çasanan pat bawi seharusnya boting ngakasa lawan prtiwi. Pangestu berarti: doa restu agar selamat (cf. swastyāstu $=$ semoga selamat). Selanjutnya perkataan Yang Mami secara umum berarti: dewa-dewa kami atau para dewa. Persoalan yang masih kurang jelas yaitu arti kalimat pada baris ke-enam. Kalimat pendek itu seharusnya berbunyi papa kabuktiha dan bukannya papa kabuktihi. Rupa-rupanya pemahat prasasti terlanjur tergesagesa membubuhkan tanda wulu (i) di atas huruf ha. Hal ini dapat dibanding dengan prasasti Gerba yang akan saya terangkan di bawah. Perkataan papa mungkin berkaitan dengan papak, artinya: penuh, tuntas, tingkat teratas (papak kabuktiha). Tetapi mungkin pula memang berbunyi papa yang berarti: sengsara, celaka (cf. papa cintraka). Dengan demikian barang siapa berani melanggar walêr (larangan) para dewa (Yang Mami), artinya kurang saling mencintai dalam perkawinan (kurang bobot seperti beratnya angkasa dan bumi) akan mendapat kutukan hidup sengsara dalam keadaan duka dan nestapa. Memang di dalam prasasti Jawa Kuno kerapkali disebut-sebut sapatha atau kutukan bagi siapa saja yang berani melanggar perintah raja (sang hyang ajña-haji prasāsti). Pendek kata batu bertulis dari Pasrujambe ini berkaitan dengan masalah atau nasihat perkawinan. Memang hal ini agak berlainan dengan nasihat perkawinan dalam masyarakat Jawa sekarang yang menekankan pada masalah bobot (pangkat, jabatan, kekayaan), bibit (orang tua dan keluarga calon mempelai: penjathat, gila, sakit menurun) dan bebet (silsilah, keturunan, status sosial). Nasihat perkawinan atau tepatnya bagaimana memilih calon istri sebetulnya sudah diungkapkan di dalam 
kitab Nitišāstra. Nyanyian V (tembang Kusumawicitra) bait 6 kitab Nitisâstra mengatakan sebagai berikut:

lwiring awalā yogya pinaka patni, wara-guna rūpādhika kula dhāni, mapês ikang ambêk ghrẹna ya susilā,

kadi panêdẹngning kusmawicitra.

Berarti lebih-kurang sebagai berikut:

Seorang wanita yang layak dijadikan istri, yang bersifat baik, cantik jelita, keluarga baik dan kaya, setidak-tidaknya yang berhati lemah-lembut dan susila, bagaikan mekarnya kembang setaman. ${ }^{15}$

Sudah jelas bahwa menurut kitab Nitiśāstra, seorang calon istri harus mempunyai beberapa sifat tertentu, yaitu:

1. bertingkah laku yang baik dan terpuji (wara-guna),

2. berupa cantik (rüpädhika),

3. dari keluarga yang baik (kula),

4. kaya-raya (dhāni).

Apabila persyaratan tersebut tidak dimiliki oleh seorang calon istri, setidak-tidaknya ia harus berbudi lemah-lembut dan bersifat susila. Dengan demikian masalah kecantikan (relatif), asal keluarga (silsilah) dan kekayaan hanya merupakan faktor penunjang belaka. tetapi yang terpenting yaitu berbudi baik (ambêk ghrêna) dan susila (suśila). Baiklah mengenai masalah perkawinan menurut konsep para pujangga lama dan baru, saya uraikan pada kesempatan lain. Masalah ini juga merupakan topik yang menarik untuk Javanologi yang bertugas meneliti dan mempelajari segala aspek kehidupan dan pengetahuan yang dimiliki orang Jawa, termasuk masalah arsitektur. kejawen, para-psikologi, fisiognomi (katuranggan), primbon, keris, wayang, mistik, babad, dongeng (folklore, legenda), dan lain-lainnya. Sebuah lembaga swasta, yaitu Lembaga Javanologi yang bernaung di bawah Yayasan Panunggalan telah didirikan di kota Yogyakarta pada tanggal 17 April 1984.16

Perlu ditambahkan di sini bahwa prasasti dari Pasrujambe yang menyangkut masalah perkawinan itu dapat dibanding dengan sebuah batu bertulis yang berasal dari Gêrba. Desa Gêrba terletak kira-kira 
$7 \mathrm{~km}$ sebelah timur-laut Kampung Wetan (jalan raya antara Kêpanjen - Jêmbêr) atau kira-kira $6 \mathrm{~km}$ di sebelah timur-laut Ampelgading (Kabupaten Malang). Sayang sekali ukuran batu tidak diketahui karena saya hanya mendapat gambarnya belaka. Ternyata batu bertulis dari Gêrba bentuk (tipe) huruf-hurufnya sama dengan batu bertulis dari Munggir (Pasrujambe). Supaya lebih jelas baiklah saya cantumkan di sini bunyi prasasti dari Gêrba yang isi selengkapnya sebagai berikut:

1. Tulusa talu (baca: tulu)

2. sa den kada (baca: kadi)

3. botang akasa (baca: boting-akasa)

4.lawan prtiwi so-

5. ga kabuktiha.

Berarti lebih-kurang:

1. Tuluslah tuluslah

2. agar seperti

3. berațya angkasa (langit)

4. dan pertiwi (bumi)

5. asal saja akan terbukti.

Prasasti dari Gêrba (Ampelgading, Kabupaten Malang) ini isinya sudah cukup jelas. Mungkin yang dimaksud dengan tulusa tulusa di sini yaitu masalah perkawinan. Jadi sama halnya dengan prasasti dari Munggir (Pasrujambe). Kalimat soga kabuktiha berarti: asal saja akan terbukti atau terlaksana. Perkataan soga sama artinya dengan bahasa Jawa Baru sa-uga (asal saja, juga).

Demikianlah uraian singkat saya mengenai prasasti yang berasal dari dukuh Munggir (desa Pasrujambe), yang tersimpan di Fakultas Sastra Universitas Jêmbêr, dan yang berasal dari desa Gêrba. ternyata prasasti yang dinyatakan tulisannya tidak diketahui, ganjil dan penelitian pada tahun 1954 tidak memberikan sesuatu hasil, setelah diteliti ulang dapat dibaca dan diketahui artinya dengan mudah. Demikian pula ternyata bahwa tipe tulisan dari Pasrujambe sama dengan tulisan dari Gêrba.

Sebagai penutup saya mengusulkan kepada yang berwewenang agar melakukan penelitian ulang di Pasrujambe secara tuntas. Arti- 
nya dilakukan pemetaan selengkapnya, penggalian percobaan, pemotretan dan melacak batu bertulis lainnya yang mungkin masih tersimpan di gundukan atau perbukitan sekitarnya. Ternyata dari jumlah sekitar 20 buah prasasti yang telah diketemukan, sepenuhnya dapat dibaca secara lancar. Mudah-mudahan pada kesempatan lain, saya mampu memberikan ulasan sepenuhnya tentang prasasti Pasrujambe yang belum saya uraikan. Terakhir kepada yang berwajib di Jawa Timur, saya menghimbau agar batu bertulis yang bertebaran di sekitar sumber Rawa tersebut mendapat perhatian sepenuhnya dan perlu pengamanan lebih lanjut. Sebelum batu-batu berharga yang bernilai sejarah purbakala itu rusak atau hilang, sebab kalau sampai demikian kita hanya dapat mengatakan 'sic transit gloria mundi'. ${ }^{17}$

Sekian dan terimakasih. 


\section{CATATAN}

1. Tembag Dandanggula itu terjemahannya sebagai berikut:

Pêpaliku (ajaran, petunjuk) hargailah agar memberkati, lagi pula selamat dan menyebabkan sehat, Pêpali itu sebagai berikut:

jangan bersikap angkuh, jangan bengis dan jangan jahil, jangan hati serakah, dan jangan panjang tangan (mencuri), jangan mengejar pujian, jangan angkuh, karena orang angkuh akan lekas mati, dan jangan berhati kiri (tidak benar.)

Siapa saja berbuat baik, tiada urung kelak menemui kebahagiaan (kemakmuran), sampai kepada semua keturunannya, jikalau kamu menjadi orang besar. memerintah orang kecil, jangan keras-keras dan seenaknya. nantinya tak akan tetap (terus), kamu menjadi pelindung (tempat bernaung), jangan sembarangan, memerintahlah yang tepat, pakailah tepa-salira.

2. Dalam bahasa Yunani disebut ambrosia (The Elixir of Life). Istilah lainnya yaitu: tirta nirmala, toya pawitra. tirta marta, amrtañjiwani tatwämrta śiwămbha, ma-ul khayat, dan lain-lain. Lihat M.M. Sukarto K. Atmodjo: Arti Air Penghidupan Dalam Masyarakat Jawa, diterbitkan oleh Proyek Javanologi. Yogyakarta, tahun 1983.

3. Ibid. hlm. 10.

4. Perkataan mahä (besar) pada hakekatnya sama dengan su (lebih). Mahämeru = Sumen. Gunung Mahämeru di India hanya bagian bawahnya saja, karena bagian puncak telah dipindahkan ke Jawa.

5. Perkataan rabut (rambut) dapat dipisahkan menjadi ra (yang mulia, awalan penghormatan) dan but (sesuatu yang dapat dicabut). Rambut memang dianggap keramat pada kelompok masyarakat tertentu, dan dianggap banyak mengandung mana (kekuatan gaib). Cf. mandau yang diberi ikatan rambut. Samson yang kehilangan rambutnya maka kekuatannya pun hilang. Ibu-ibu kita sewaktu menyisir rambut yang lepas juga disimpan baik-baik. 
6. Penelitian saya di Faksas Universitas Jêmbêr diterima dengan baik dan simpatik oleh Dekan Faksas (Bapak Drs. Soedardi) bersama staf Dosen lainnya. Sedangkan dari Balai Arkeologi Yogyakarta saya disertai Sdr. Drs. R.M. Susanto.

7. Dalam bahasa Yunani-Latin diagramma berarti: gambar. Lihat M.J. Koenen - J. Endepols: Verklarend Handwoordenboek der Nederlandse Taal, J.B. Woters, 1939, hlm. 205.

8. Kalimat itu berarti: tiga tahun tidak ada raja.

9. Mula-mula saya membaca Sang Nawakunda di Faksas Jêmbêr. Setelah tiba di rumah dan saya banding dengan pertulisan lainnya dari Pasrujambe ternyata harus dibaca Sang Nawakrnda. Pada hakekatnya perkataan kunda sama artinya dengan krnda (keranda, wadah, tungku).

10. Misalnya berkaitan dengan sembilan wadah (tungku) yang keramat.

11. Nama dukuh Munggir dan desa Pasrujambe adalah nama yang dikenal sekarang. Nama aslinya pada jaman dahulu (Majapahit) tidak (belum) diketahui. Tetapi mungkin juga nama itu tetap tidak berubah sejak jaman dahulu.

12. Tirthāyātra yaitu jiarah ke tempat suci di dekat sumber air atau sungai. Kenyataan di dekat batu bertulis terdapat sumber Rawa yang jernih airnya. Yätra berarti: perjalanan. jiarah, tirthä: air suci, siddha: sukses, berhasil.

13. Binatang laut (Molukse krab) jantan betina yang selalu berhimpitan. Lir mimi lan mintuna menggambarkan dua orang laki-laki perempuan yang tidak pernah terpisahkan. Lihat Dr. Th. Pigeaud: Javaans-Nederlands handwoordenboek. J.B. Wolters. 1938, hlm. 283.

14. Ungkapan itu berarti: keseluruhan, semua. Tetapi yang penting di sini yaitu langit yang dianggap laki-laki dikatakan tertelungkup, sedangkan bumi yang dianggap perempuan tertelentang. Jadi menimbulkan kesan perkawinan atau kesatuan antara langit dan bumi yang kekal abadi. Air hujan pun kadang-kadang dianggap sebagai zat laki-laki (sperma) yang menyuburkan tanah (pembuahan).

15. Menurut terjemahan Prof. Dr. Poerbatjaraka bunyinya sebagai berikut (Nitiśāstra hlm. 56).

Een vrouw, geschikt om tot echtgenoote genomen te worden is zij, die van voorname deugd, voortreffelijke schoonheid, goede familie en rijk is; een zachte inborst heeft, gevoelig en van goed karakter is, gelijk veelkleurige bloemen in volle pracht. 
16. Pendiri Lembaga Javanologi sebanyak 7 orang. yaitu: 1 Prof. Dr. Soero so M.A.. 2. KPH Mr. Soedarisman Poerwokoesoemo. 3. H. Karkoni Partokusuma (Kamajaya). 4. M. Wonohito (almarhum). 5. Winotoparar tho. 6. Ki Y. Padmapuspita. 7. Drs. M.M. Sukarto Kartoatmodjo.

17. Dalam kamus M.J. Koenen - J. Endepols diterjemahkan aldus gaat de glorie der wereld voorbij (demikianlah kebesaran dunia telah berlalu). hlm. 925. 


\section{DAFTAR PUSTAKA}

Brandes, J. 1897. Pararaton (Ken Arok) of het Boek der Koningen van Tumapel en van Majapahit. Uitgegeven en Toegelicht door Dr. J. Brandes. VBG. XLIX. hlm. 1 - 314.

Koenen M.J., Endepols, J. 1939. Verklarend Handwoordenboek der Nederlandse Taal. J.B. Wolters, Groningen, Batavia.

Pigeaud. Th. 1938. Javaans-Nederlands Handwoorden boek. J.B. Wolters, Groningen, Batavia.

Pott. P.H. 1966. Yoga and Yantra. Translation Series 8. Kon. Inst. voor Taal-, Land-en Volkenkunde. The Hague - Martinus Nijhoff

Poerbatjaraka, R. Ng. 1933 Nitisastra, Bibliotheca Javanica 4, Kon. Bat . Gen. van Kunsten en Wetenschappen. A.C. NIX \& Co. Bandoeng.

Sukarto Kartoatmodjo, M. M. 1983. Arti Air Penghidupan Dalam Masyarakat Jawa. Seri Penerbitan Proyek Javanologi No. 2. Th. ke. 1. Dep. Pendidikan dan Kebudayaan. Proyek Javanologi. Yogyakarta.

Soetardi Soeryohoedoyo, R.M. 1980. Pepali Ki Ageng Sela, diterbitkan oleh CV "Citra Jaya". Surabaya.

Soekmono, 1962. Laporan Tahunan 1954 Dinos Purbakala. Departemen PP dan K. Djakarta 1962. 


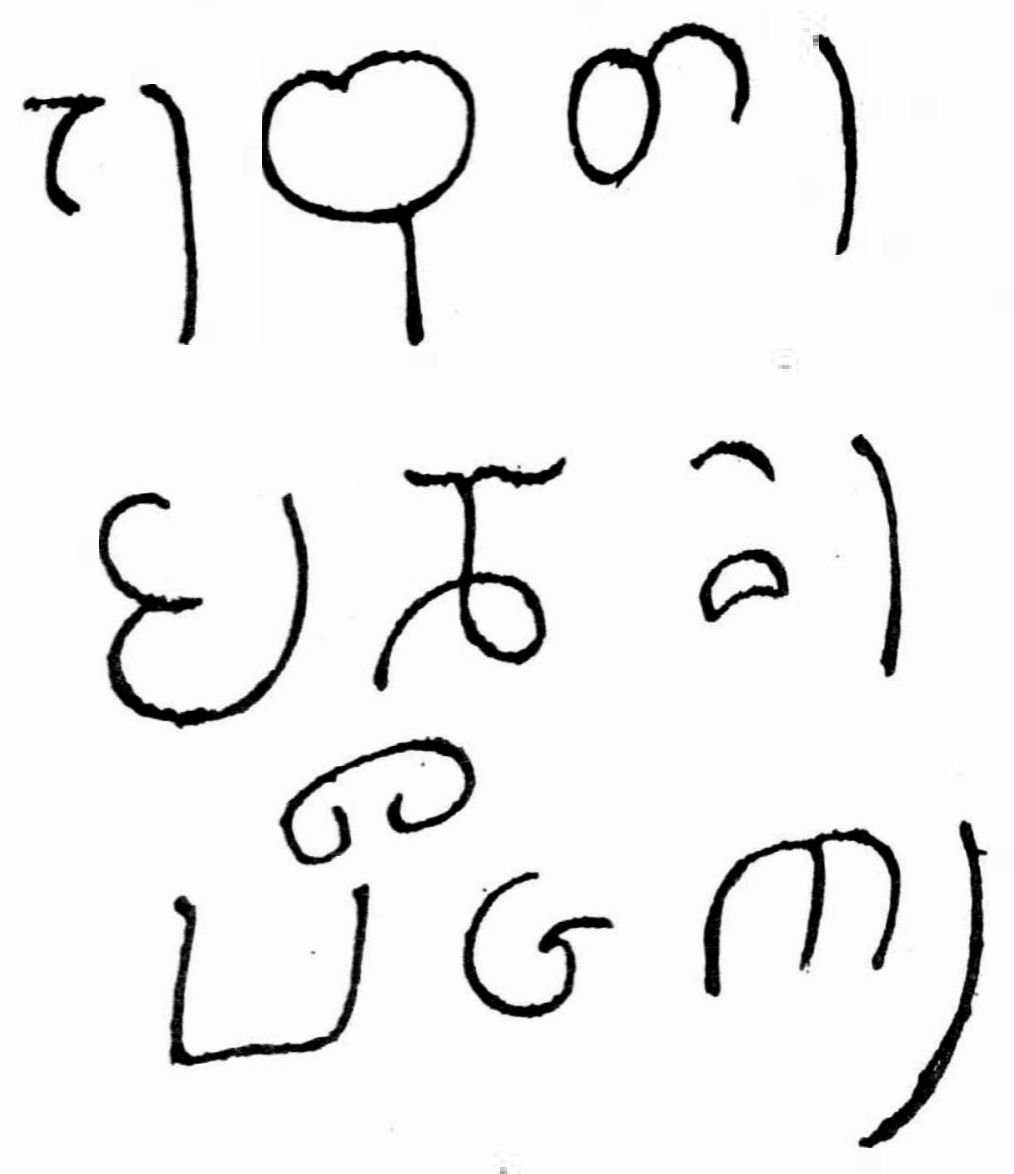

Gambar No. $1^{\bullet}$ 
I
II


III

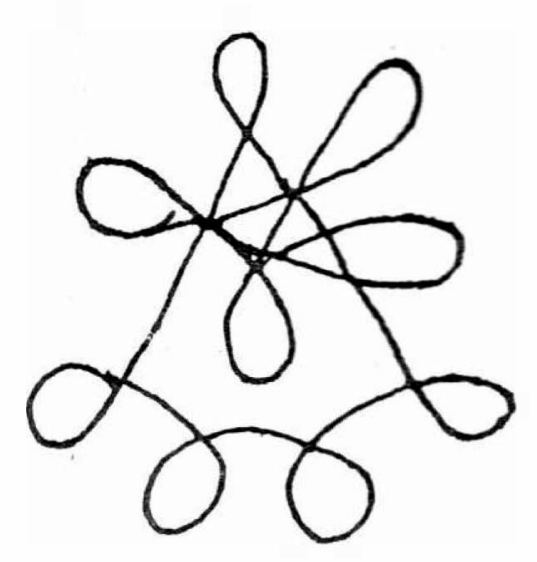

Gambar No. 2 


$$
\begin{aligned}
& \text { m } m^{c} u_{2}(2 \pi) \sigma \\
& \text { WEE, Pिती } \\
& \text { ग) } 2 \omega \text { à } 70.2 \mathrm{C} \\
& \text { ธ) } \pi[209 \text { 的 } \\
& 27 \mathrm{NO} \text { o) } \mathrm{z}_{0} \text { क } \mathrm{C} \\
& \text { Uนm@ }
\end{aligned}
$$

Gambar No. 3 


$$
\begin{aligned}
& \text { 2๑, } N_{7} \text { \& } N_{7} \\
& \text { \% } 2[\widehat{\sigma}) \mathrm{C} \\
& \text { \& } \\
& \text { NOJ) } \overbrace{}^{5} \stackrel{5}{0} \text { \& } \\
& \left.n m 0_{7} m\right) \text { กับ }
\end{aligned}
$$

Gambar No. 4 